\title{
IDENTIFICATION OF POTENTIAL DRUG RELATED PROBLEMS OF IMPROPER DOSAGE AND ADVERSE DRUG REACTIONS CATEGORIES IN OSTEOARTHRITIS OUTPATIENTS IN RSUD JOMBANG 2016
}

\author{
${ }^{1}$ Ayu Tria Nurjannah Muslim, ${ }^{2 *}$ Abdul Hakim, dan ${ }^{2}$ Meilina Ratna Dianti \\ ${ }^{1}$ Student of Department of Pharmacy, Faculty of Medical and Health Sciences, Maulana Malik Ibrahim State \\ Islamic University \\ Jl. Gajayana No. 50 Malang 65144 \\ ${ }^{2}$ Department of Pharmacy, Faculty of Medical and Health Sciences, Maulana Malik Ibrahim State Islamic \\ University \\ Jl. Gajayana No. 50 Malang 6514 \\ Co-author : ayutrianurjannah@gmail.com \\ *Corresponding author : ahrizfit@gmail.com \\ Co-author : meilina_rd@yahoo.com
}

\begin{abstract}
Osteoarthritis is a chronic disorder of synovial joints, characterized by progressive softening and disintegration of cartilage in joints. This is the most common type of arthritis in Indonesia with prevalence about 23.6 to $31.3 \%$ and generally suffered by middle age patients. Drug therapy for treating osteoarthritis is NSAIDs, supplements and corticosteroids. The increasing number of available drugs, drug users and more complex drug regimens caused more side effect and potential drug interaction and lead to another problem, it is Drug Related Problems. The purpose of this study was to identify potential Drug Related Problem categories of improper dosage and Adverse Drug Reactions in osteoarthritis outpatient in RSUD Jombang during 2016. This research is a non-experimental descriptive study conducted retrospectively, carried out in March 2017 at RSUD Jombang. Research sample is 87 respondents of osteoarthritis outpatient which taken by systematic random sampling method. The data presented in percentage of improper dosage and Adverse Drug reactions potential case. The result found potential of improper dosage in respondent about 82,76\% and Adverse Drug Reactions about 20,69\%.
\end{abstract}

Keywords: Adverse Drug Reactions, Improper Dosage, Osteoarthritis, Potential of Drug Related Problem

\section{INTRODUCTION}

Osteoarthritis is a chronic synovial joint disorder characterized by progressive softening and destruction of joint cartilage along with cartilage and bone growth in osteophytes, cyst formation and sclerosis in the bone subchondral, mild synovitis and fibrosis capsule. The disease is most common in middle-aged people, although young people may be affected as a result of injury [1]. Drugs commonly used for osteoarthritis treatment are pain relievers such as Non 
Steroid Anti Inflammatory (NSAID). If the case has reached moderate to severe, it can be followed by glucosamine therapy, chondroitin sulfate or hyaluronidase acid that serves as a bone enhancer. In some cases, treatment with corticosteroids is also frequently performed [2].

The increasing number of available drugs, drug users as well as more complex drug regimens leads to more side-effects and drug interactions that complicate treatment follow-up $[3,4]$. Drug Related Problems (DRPs) or can also be called drug-related problems can be defined as an event or circumstance involving drug therapy that actually or potentially interfere with the desired therapeutic objective [5]. Cipolle categorized DRPs into 7 groups: non-treatment indications, drug selection inaccuracies, dose inaccuracies, unproven drugs, ADRs, inaccuracy of laboratory monitoring and patient disobedience [6,7]. The most frequently of DRPs cases are ADRs, dose inaccuracies, and drug prescription that refer to insecure therapy [8]

Dose inaccuracy can be caused by; doses too low or too high, blood levels of drugs above or below the range of therapy, frequency of administration, duration of therapy, and methods of administration of drugs are inappropriate, inappropriate prophylactic timing (e.g surgical prophylaxis given too early), and doses raised too fast [6]. ADRs can be caused by; anomaly response from patient (allergy to certain drug), anomaly response caused by coexistence, anomaly during presentation and administration of drug in patient body (occurrence of inappropriate bioavailability or medication administration method) and drug interaction [9].

To prevent the case of DRPs, accurate control of drug therapy in patients is urgently needed, and this is one of the pharmacist's duties as a skilled healthcare professional. One of ways to control the accuracy of therapy is to review the accuracy of dosage and monitoring drug interactions. It written in the Regulation of the Minister of Health of RI number 58 in 2014 that one of the pharmaceutical services in the hospital includes clinical pharmacy services where one of his duties to conduct history of drug use in patients [9].

RSUD Jombang is one of hospitals in Jombang, East Java with the high number of joint patients. Based on hospital medical record data obtained through field pre-survey by researcher in 2017, outpatients which diagnosed with osteoarthritis in Jombang Hospital were 830 people, and 3 people with inpatient status. Based on literature results revealed that no DRP-related studies had been conducted in Jombang General Hospital especially osteoarthritis patients. 


\section{RESEARCH METHODS}

This is a non experimental descriptive study using patient medical record in 2016. The study was conducted in RSUD Jombang in March 2017. Data analysis was done descriptively by identifying the level of Potential Drug Related Problems of improper dosage and Adverse Drug Reactions on prescriptions and presented in table and percentage form.

Population in this study were all medical records of outpatient osteoarthritis patients in RSUD Jombang from $1^{\text {st }}$ of January to $31^{\text {st }}$ of December 2016. Eighty seven samples were selected by systematic random sampling from 830 total of medical records. Sampling is done by dividing the population into groups of no more than $\mathrm{N} / \mathrm{n}(\mathrm{N}$ is the population whereas $\mathrm{n}$ is the number of samples to be taken), a number of samples is taken from each group until 87 samples.

Dosage analysis was doing by Pharmacotherapy, a Pathophysiologic Approach, book by Joseph T Dipiro (2008) and for ADRs cases (drug interactions) by Stockley's Drug Interactions 8th edition by Karen Baxter (2008). Potential dose inaccuracy is measured by 2 parameters ie excessive dose / less and high / low frequency. The potential ADRs are identified from potential adverse interactions on prescription.

\section{RESULTS AND DISCUSSION}

\section{Gender}

The most respondents suffered osteoarthritis were women, about 68 people $(78.16 \%)$ while men only 19 (21.84\%).

Age

In this study, respondents who suffer from osteoarthritis are from the late adolescents, early adulthood, late adulthood, early old, elderly and oldest (see table 1).

\section{BMI (Body Mass Index)}

In this study, respondents with excess body weight (overweight) is quite high about 30 people while patient with obesity only 1 person, normal weight respondent about 55 people and underweight respondent only 1 person (see table 2).

\section{Pain location}


The location of the joints most frequently affected by osteoarthritis is foot joint about 71 respondents $(81.61 \%)$. Osteoarthritis hip only experienced by 4 people $(4.60 \%)$ and 12 people (13.79\%) experienced pain in other parts of body such as elbows, neck, hands and more than one joint.

\section{Uric Acid Level}

Respondents with high uric acid levels are about 5 people (5.75\%), 21 people had normal uric acid levels $(24.14 \%)$ and 61 people $(70.1 \%)$ had unknown uric acid levels.

\section{Diagnosis of Respondents}

Respondents with uncomplicated diagnosis of OA are about 67 people (77.01\%), 15 people had one comorbid disease (17.24\%), 4 people had two comorbidities (4.60\%) and 1 people had 3 comorbidities $(1,15 \%)$ (see table 3 )

\section{Drug Use Profile}

The number of drugs given to outpatient OA respondents in RSUD Jombang in 2016 is at least 1 type of drug and at most 6 types of drugs. The number of prescriptions in total is 232 prescriptions. There are 1-2 drug given about 49 times (16,78\%), 3-4 drug about 235 times $(80,48 \%)$ 5-6 drugs given about 8 times $(2,74 \%)$. The most prescribed drug was AINS about 273 times $(30.30 \%)$ of the total 901 drug preparations (see figure 1 ).

\section{Dose inaccuracy}

Respondents with an inaccurate dose on prescription are 72 people and respondent with accurate dose are 15 people. Based on total number of drugs received by respondents from 901 drugs, 214 drug was inappropriate dose and 687 drug was appropriate. From total 214 drugs, which 49 drugs were too high doses, 12 drugs were under dose, 118 drugs were high frequency and 35 drugs were low frequency. The most potent dose-induced drug is piroxicam ( 88 cases of high frequency) (see table 4 and 5 and figure 2 for graphic).

\section{Adverse Drug Reactions}

A total of 18 respondents $(20.69 \%)$ experienced potential ADRs on prescriptions while 69 others $(79.31 \%)$ did not. As for 292 total recipes, 23 recipes $(7.88 \%)$ have potential ADRs and 269 recipes $(92.12 \%)$ others did not. From 25 total cases were divided into 3 types of potential adverse drug interactions: NSAIDs + corticosteroids, NSAIDs + NSAIDs and paracetamol + ranitidine (see table 6). 


\section{CONCLUSION}

The percentage of potential dose insufficiency in outpatient osteoarthritis patients was 82.76\% while the percentage of Adverse Drug Reactions potential in outpatient osteoarthritis patients was $20.69 \%$. For further research can be focused on the identification of actual Drug Related Problems in osteoarthritis patients, especially regarding the inaccurate dose and Adverse Drug Reactions.

\section{REFERENCES}

[1] Fauci., Braunwald., Kasper., Longo H., Jameson., and Loscalzo. 2008. Principles Of Internal Medicine. Disorder immune system, connecting tissue and joint, Edisi ke 17. US; The McGraw-Hill.

[2] Dipiro, J.T., Robert L.T., Gary C.Y., Gary R.M., Barbara G.W., \& Michael P. 2008. Pharmacotherapy A Pathophysiologic Approach Seventh Edition. USA: The Mc. Graw Hill Company.

[3] Ruths S, Viktil KK, Blix HS. 2007. Classification of drug-related problems. Tidsskr: Nor Laegeforen, 127:3073-6

[4] Bereket M.T., Daniel Daba, and Belete Habte. 2014. Drug related problems among medical ward patients in Jimma university specialized hospital, Southwest Ethiopia. Journal of Research in Pharmacy Practice: 3(1).

[5] [PCNE] Pharmaceutical Care Network Europe Foundation. 2006. Classification for Drug related problems (29-05-06 V 5.01).

[6] Cipolle, RJ., Strand, LM, Morley, PC. 1998. Drug Therapy Problem, In Pharmaceutical Care Practie The Clinician's Guide. New York: The McGraw Hill Companies.

[7] Mahmoud M.A. 2008. Drug Therapy Problems and Quality of Life in Patients with Chronic Kidney Disease. Unversiti Sains Malaysia.

[8] Ernst, Michael et al. 2003. Drug Related Problems and Quality of Life in Arthritis and Low Back Pain Sufferers. ISPOR, 51-58. 
[9] Sigonda, M. Ndomondo. 2003. Guidelines For Monitoring And Reporting Adverse Drug Reactions (ADRs). Journal of Tanzania Food and Drugs Authority.

[10] Kemenkes RI. 2014. Standar Pelayanan Rumah Sakit. Menteri Keseharan RI, Jakarta.

Table 1. Respondents profile based on age

\begin{tabular}{clccc}
\hline \multicolumn{1}{c}{ Gender } & \multicolumn{2}{c}{ Age categories } & Total (People) & $\begin{array}{c}\text { Percentage } \\
(\%)\end{array}$ \\
\hline Women & Late adolescence $(17-25$ th) & 2 & 2,30 \\
& Early adulthood & $(26-35$ th) & 3 & 3,45 \\
& Late adulthood & $(36-45$ th) & 8 & 9,20 \\
& Early old & $(46-55$ th) & 18 & 20,69 \\
& Elderly & $(56-65$ th) & 22 & 25,29 \\
& Oldest & $(>65$ th $)$ & 15 & 17,24 \\
\hline
\end{tabular}

Table 1. (sequel) Respondents profile based on age

\begin{tabular}{llcc}
\hline Gender & \multicolumn{1}{c}{ Age categories $^{*}$} & Total (People) & $\begin{array}{c}\text { Percentage } \\
(\%)\end{array}$ \\
\hline Man & Remaja akhir $(17-25$ th) & 1 & 1,15 \\
& Dewasa awal $(26-35$ th) & 0 & 0 \\
& Dewasa akhir $(36-45$ th) & 0 & 0 \\
& Lansia awal (46-55 th) & 5 & 5,75 \\
& Lansia akhir (56-65 th) & 6 & 6,90 \\
& Manula (>65 th) & 7 & 8,05 \\
& & $\mathbf{8 7}$ & $\mathbf{1 0 0}$ \\
\hline
\end{tabular}

*Age category based on Ministry Of Health of RI in 2009

Table 2. Respondents profile based on BMI

\begin{tabular}{lccc}
\hline \multicolumn{1}{c}{ BMI } & Total (People) & Percentage (\%) \\
\hline Underweight $(\mathbf{1 8 , 5 )}$ & 1 & 1,15 \\
Normal $\mathbf{( 1 8 , 5 - 2 4 , 9 )}$ & 55 & 63,22 \\
Overweight $(\mathbf{2 5 , 0 - 2 9 , 9 )}$ & 30 & 34,48 \\
Obesity (>30) & 1 & 1,15 \\
& Total & $\mathbf{8 7}$ & $\mathbf{1 0 0}$ \\
\hline
\end{tabular}


Table 3. Comorbidities profile

\begin{tabular}{lcc}
\hline \multicolumn{1}{c}{ Comorbidities } & Total case & Percentage (\%) \\
\hline Low Back Pain & 9 & 34,62 \\
Arthritis Gout & 3 & 11,54 \\
Diabetes Mellitus & 3 & 11,54 \\
Hypercholesterolemia & 3 & 11,54 \\
Fractur & 2 & 7,69 \\
Charcot & 2 & 7,69 \\
Hypertension & 2 & 7,69 \\
Osteoporosis & 1 & 3,85 \\
Spondylitis TB & 1 & 3,85 \\
Total & $\mathbf{2 6}$ & $\mathbf{1 0 0}$ \\
\hline
\end{tabular}

Table 4. Improper dose cases base on number of respondent

\begin{tabular}{lcc}
\hline \multicolumn{1}{c}{ Categories } & Total (People) & Percentage (\%) \\
\hline $\begin{array}{l}\text { Respondents with improper dose } \\
\text { case on prescription }\end{array}$ & 72 & 82,76 \\
$\begin{array}{l}\text { Respondents with proper dose on } \\
\text { prescription }\end{array}$ & 15 & 17,24 \\
\multicolumn{1}{c}{ Total } & $\mathbf{8 7}$ & $\mathbf{1 0 0}$ \\
\hline
\end{tabular}

Table 5. Improper dose cases base on number of drug preparations

\begin{tabular}{ccc}
\hline Categories & Total (drug) & Percentage (\%) \\
\hline Drug with improper dose case & 214 & 23,75 \\
Drug with proper dose & 687 & 76,25 \\
Total & $\mathbf{9 0 1}$ & $\mathbf{1 0 0}$ \\
\hline
\end{tabular}


Figure 1. Drugs distribution based on class therapy

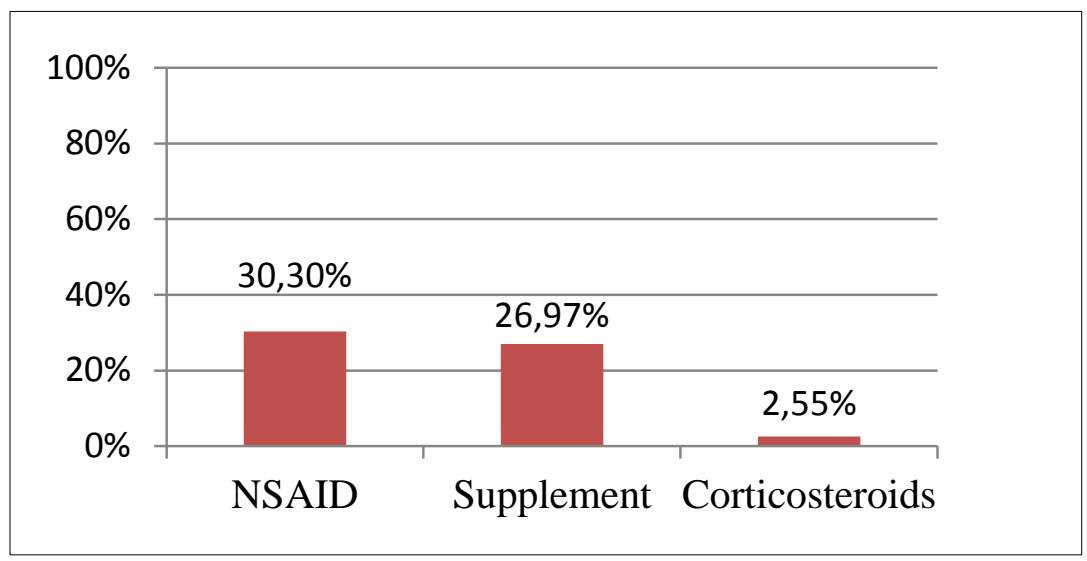

Figure 2. Graphic of improper dose cases

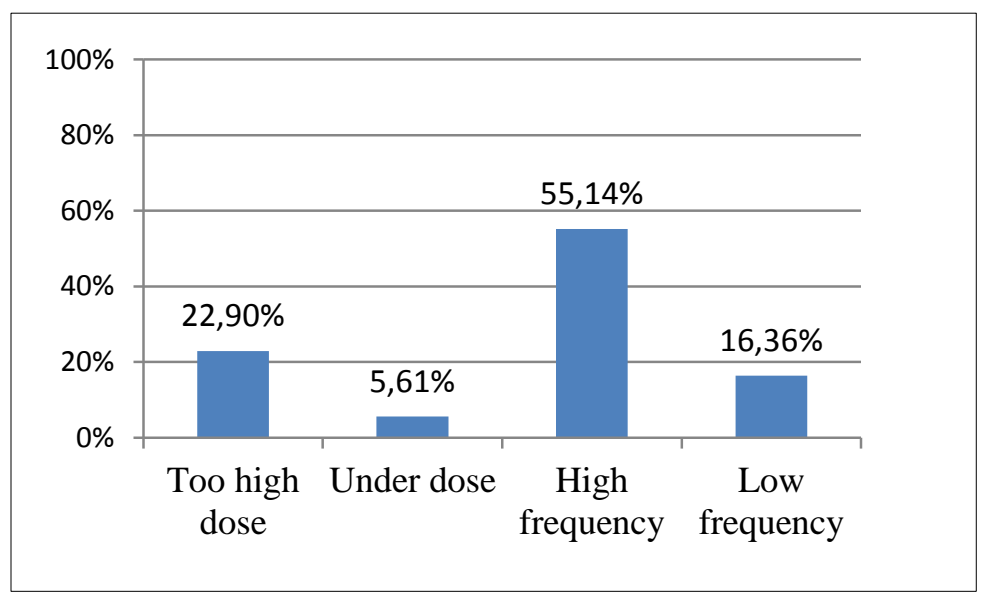

J. Islamic Pharm., an open access journal ISSN : 2527-6123 